\title{
Influence of Subunit Interface Mutations on Kinetic and Dynamic Properties of Alkaline Phosphatase from E. coli
}

\author{
Matilda Šprung, Viljemka Bučević-Popović, Barbara Soldo, \\ Maja Pavela-Vrančić, and Stjepan Orhanović* \\ Department of Chemistry, Faculty of Science, University of Split, N. Tesle 12, HR-21000 Split, Croatia
}

RECEIVED AUGUST 29, 2012; REVISED DECEMBER 11, 2012; ACCEPTED JANUARY 4, 2013

\begin{abstract}
Mutations, replacing amino acids involved in the formation of hydrogen bonds between subunits of dimeric alkaline phosphatase, have been introduced. Influence of mutations on kinetic properties and structural stability of mutant enzymes was established. In addition, alterations in protein dynamic properties have been studied using room temperature phosphorescence. Kinetic properties of both mutant enzymes were virtually the same, differing from the wild type enzyme in the $k_{\text {cat }}$ value that was almost twice lower. Changes in protein dynamic properties of mutant proteins, compared to the wild type enzyme, did not parallel changes in kinetic properties suggesting that an alteration in the rigidity of the Trp109 environment is not responsible for the reduction of kinetic properties. Instead, combined kinetic and dynamic consequences of introduced mutations suggest that breaking of specific links, involved in transmission of conformational change, could be responsible for altered kinetic properties. (doi: 10.5562/cca2168)
\end{abstract}

Keywords: room temperature phosphorescence, acrylamide quenching, kinetic properties, protein dynamics, subunit interface

\section{INTRODUCTION}

Alkaline phosphatase (AP) from Escherichia coli (E.C. 3.1.3.1), is a dimeric metalloenzyme that catalyzes the hydrolysis of a wide variety of phosphomonoesters. It belongs to a group of oligomeric enzymes known to display deviations from Michaelis-Menten kinetics, resembling negative cooperativity and half-of-the sites reactivity. ${ }^{1-5}$

It has been proposed that asymmetry of dimeric AP underlies such a kinetic behavior. ${ }^{6}$ A plausible model based on subunit asymmetry, describing the advantages of homodimeric over monomeric enzymes, has been outlined. ${ }^{7}$ Based on crystal structure analysis, ${ }^{8}$ it has been anticipated that the $\beta$-pleated sheet, stretching from underneath the active site to the subunit interface, has an important role in conformational changes supporting the catalytic cycle. The importance of interfacemediated communication between the subunits has been assessed by site directed mutagenesis. Introduction of alanine instead of Thr81, involved in hydrogen bonding between neighboring $\beta$-pleated sheets, resulted in a mutant enzyme with altered kinetic properties. ${ }^{9}$ The decreased reaction rate of the T81A mutant, with almost twofold reduction in $k_{\text {cat }}$, stresses the importance of subunit interface interactions for the kinetic mechanism. Altered kinetic properties could be the consequence of a change in protein rigidity, or disruption of the bonding interaction involved in transmission of conformational change between the active sites on neighboring subunits. ${ }^{10}$ Structural rigidity, conformational and dynamic properties of proteins could be assessed by monitoring the phosphorescence properties of a reporter group located in the vicinity of the protein region of interest. ${ }^{11}$ Phosphorescence lifetime represents a sensitive probe of local protein rigidity ${ }^{12,13}$ and could be correlated to changes in rigidity triggered by binding of substrates or allosteric effectors. ${ }^{14-16}$ Tryptophan phosphorescence at room temperature could provide information regarding the dynamic changes in protein structure occurring on a millisecond to second time scale. ${ }^{12,17-21}$ Besides an intrinsic lifetime of the triplet probe, the rate of migration of a phosphorescence quenching solute, such as acrylamide, into the proximity of the phosphorescent probe provides information on the local segmental flexibility and structural fluctuations. ${ }^{22}$ AP contains only one phosphorescing aromatic residue, Trp109. The exceptionally rigid and solvent-inaccessible environment in the inner core of the macromolecule provides for a very long phosphorescence lifetime, up to two seconds. ${ }^{11-23}$

\footnotetext{
* Author to whom correspondence should be addressed. (E-mail: stipe@pmfst.hr)
} 
Trp109 is connected to the active site via a rigid $\alpha$-helical rod and to the subunit interface via a $\beta$-sheet that envelopes $\operatorname{Trp} 109 .^{8}$ Therefore, the triplet lifetime of this residue could be used as a sensitive monitor of the conformational state in the polypeptide region that connects the active sites of neighboring subunits.

In this study, phosphorescence lifetime and quenching experiments were performed in conjunction with kinetic and structural stability studies in order to provide clues about the relationship between protein dynamic properties and its functional characteristics. Consequences of additional weakening of the link between the $\beta$-sheets at the same site were probed by a new hydrogen bond removing mutation, created by substituting Gln83 with Leu.

Kinetic properties of single T81A and double T81A/Q83L mutant proteins and the wild-type enzyme have been compared in Tris $/ \mathrm{HCl}(c$ (Tris $)=1 \mathrm{~mol} \mathrm{dm}^{-3}, \mathrm{pH}$ $=8.0$ ). Rigidity of the protein structure has been assessed by measuring the phosphorescence lifetime and the rate of acrylamide diffusion. Structural stability of wild-type AP and mutants carrying mutations at the subunit interface, were assessed by susceptibility to thermal denaturation.

\section{EXPERIMENTAL}

\section{Site-directed Mutagenesis}

The wild type AP gene (phoA) was cloned into the pET11d expression vector (Stratagene) and transformed into the $E$. coli strain JM109, as described by Orhanović et al. ${ }^{9}$

Site-directed mutagenesis was conducted using the GeneEditor $^{\mathrm{TM}}$ mutagenesis system (Promega). The mutagenic oligonucleotide introduced three mutations into the phoA sequence, one to replace Thr81 (ACC) with alanine (GCC), one to replace Gln83 (CAA) with leucine (CTA) and a silent mutation in the codon for Gly82 (GGG to GGC) to create a NaeI restriction site. The sequence of the mutagenic oligonucleotide, with altered bases underlined, is:

(5'-GATGCCTTACCGCTTG GCCGGCCTATACACTCA CTATGCG-3').

Mutant plasmids were identified by NaeI restriction analysis. Mutations were verified by sequencing the entire phoA gene at Macrogen, Seul, S. Korea.

\section{Protein Expression and Purification}

The E. coli strain E15, carrying a deletion in the phoA gene, was transformed with the pET11d expression vector containing the phoA gene under control of the T7 promotor. The E15 strain was co-transformed with the pGP1-2 plasmid containing the gene for T7 RNA polymerase under control of a thermolabile repressor. Bacterial cultures were grown in $\mathrm{LB}$ medium at $30{ }^{\circ} \mathrm{C}$ and $220 \mathrm{rpm}$ to an $\mathrm{OD}_{600}$ of about 0.7 . Protein expression was induced by heating the culture in a water bath at $42{ }^{\circ} \mathrm{C}$ for $45 \mathrm{~min}$. The cultures were subsequently grown overnight at $37^{\circ} \mathrm{C}$. Bacterial cells were harvested by centrifugation at $6500 \times g$ for $15 \mathrm{~min}$ and subjected to cold osmotic shock. Prior to thermal denaturation of heat sensitive proteins at $75^{\circ} \mathrm{C}$ for $15 \mathrm{~min}$, a solution of $\mathrm{ZnCl}_{2}\left(c=31 \mu \mathrm{mol} \mathrm{dm}{ }^{-3}\right)$ in Tris $/ \mathrm{HCl}(c$ (Tris) $=0.62 \mathrm{~mol}$ $\left.\mathrm{dm}^{-3}, \mathrm{pH}=7.6\right)$, was added to the periplasmic fraction to obtain a final $\mathrm{Zn}^{2+}$ concentration of $c\left(\mathrm{Zn}^{2+}\right)=1 \mu \mathrm{mol}$ $\mathrm{dm}^{-3}$ and a final Tris concentration of $c$ (Tris) $=20 \mathrm{mmol}$ $\mathrm{dm}^{-3}$. Measurements of AP activity have shown no activity change during thermal denaturation. Denatured impurities were separated by centrifugation at $9000 \times g$ for $20 \mathrm{~min}$. The protein sample was applied to an anion exchange Q6 column (BioRad). The fraction displaying the highest activity contained essentially pure AP, as revealed by SDS-PAGE. The protein concentration in purified samples was determined according to Bradford, using BSA (bovine serum albumin) as a standard. ${ }^{24}$

\section{Kinetic Analysis}

Enzymatic activity was determined by measuring the absorbance change at $405 \mathrm{~nm}$ and $298 \mathrm{~K}$, due to an increasing concentration of the reaction product, p-nitrophenol (pNP), using the Lambda 40 Bio spectrophotometer (Perkin Elmer, Norwalk, USA). Activity was measured in a reaction mixture, containing $2.3 \mathrm{~cm}^{3}$ of Tris $/ \mathrm{HCl}\left(c\right.$ (Tris) $\left.=1 \mathrm{~mol} \mathrm{dm}{ }^{-3}, \mathrm{pH}=8.0\right), 0.100 \mathrm{~cm}^{3}$ of enzyme solution in Tris/ $\mathrm{HCl}\left(c\right.$ (Tris) $=20 \mathrm{mmol} \mathrm{dm}^{-3}$, $\mathrm{pH}=7.6)$, and $0.100 \mathrm{~cm}^{3}$ of substrate solution ( $p$-nitrophenyl phosphate hexahydrate, disodium salt; pNPP) of an appropriate concentration. Kinetic analysis was performed using pNPP as substrate at concentrations ranging from $c=0.01$ to $1 \mathrm{mmol} \mathrm{dm}^{-3}$ Analysis was also done in the presence of a known competitive inhibitor, inorganic phosphate, in concentrations of $c=$

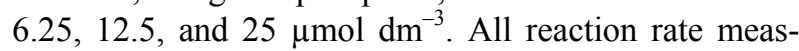
urements were performed in duplicate, and the determination of kinetic constants was performed in triplicate. Kinetic constants were determined with GraFit (Erithacus Software Limited), nonlinear regression data analysis software. Experimental data were fitted to the Michaelis-Menten equation describing the dependence of the reaction rate on substrate concentration in the presence of a competitive inhibitor or without it.

\section{Phosphorescence Measurements}

Protein samples were resuspended in Tris $/ \mathrm{HCl}(c$ (Tris) $=$ $20 \mathrm{mmol} \mathrm{dm}^{-3}, \mathrm{pH}=7.6$ ), at a final concentration ranging from $c=4$ to $5 \mu \mathrm{mol} \mathrm{dm}{ }^{-3}$. Prior to phosphorescence measurements, it was essential to remove oxygen from all samples. Deoxygenation of proteins was conducted by repeated application of vacuum and inlet of pure $\mathrm{N}_{2}$, according to Banks and Kervin. ${ }^{25}$ Upon addition of 
Table 1. Kinetic properties, first order rate constant for thermal denaturation and quenching constant of wild-type AP from $E$. coli, the T81A and T81A/Q83L mutant proteins (kinetic properties were determined in Tris $/ \mathrm{HCl}, c$ (Tris) $=20 \mathrm{mmol} \mathrm{dm}^{-3}, \mathrm{pH}=7.6, T=298 \mathrm{~K}$ )

\begin{tabular}{lccccc}
\hline Enzyme & $K_{m} / \mu \mathrm{mol} \mathrm{dm}^{-3}$ & $K_{i} / \mu \mathrm{mol} \mathrm{dm}$ & $k_{\text {cat }} / \mathrm{s}^{-1}$ & $k_{1} / 10^{-3} \mathrm{~s}^{-1}$ & $\left.k_{\mathrm{q}} / \mathrm{dm}^{3} \mathrm{~mol}^{-1} \mathrm{~s}^{-1}\right)$ \\
\hline Wild-type AP* & $7.8 \pm 0.3$ & $6.1 \pm 0.2$ & 61.84 & $0.80 \pm 0.05$ & $0.19 \pm 0.006$ \\
T81A* & $7.3 \pm 0.2$ & $6.5 \pm 0.2$ & 36.98 & $1.64 \pm 0.1$ & $0.13 \pm 0.007$ \\
T81A/Q83L & $8.6 \pm 0.3$ & $7.7 \pm 0.4$ & 36.35 & $3.20 \pm 0.3$ & $0.32 \pm 0.019$ \\
\hline
\end{tabular}

* Kinetic properties $\left(K_{m}, K_{i}\right.$ and $\left.k_{\text {cat }}\right)$ of the wild type AP and T81A mutant were determined previously. ${ }^{9}$

appropriate aliquots of an acrylamide stock $(c=7.5 \mathrm{~mol}$ $\left.\mathrm{dm}^{-3}\right)$, samples were deoxygenated again. All luminescence measurements were carried out at $293 \mathrm{~K}$.

Phosphorescence measurements were performed on a Perkin Elmer fluorimeter LS 55 using Biolight PhosDecay software. Upon excitation at $295 \mathrm{~nm}$ phosphorescence decay was monitored at $445 \mathrm{~nm}$, with a 1 ms cutoff. The decay signal was analyzed and fitted to a single exponential decay curve.

\section{Thermal Inactivation}

Samples of appropriate concentration in Tris/ $\mathrm{HCl}(c($ Tris $)=$ $20 \mathrm{mmol} \mathrm{dm}^{-3}, \mathrm{pH}=7.6$ ), were incubated at $353 \mathrm{~K}$ in a "dry-block" thermostat. Aliquots $\left(0.100 \mathrm{~cm}^{3}\right)$ were withdrawn at $5 \mathrm{~min}$ intervals during $45 \mathrm{~min}$, and assayed for enzyme activity in Tris $/ \mathrm{HCl}\left(c\right.$ (Tris) $=1 \mathrm{~mol} \mathrm{dm}^{-3}, \mathrm{pH}=$ $8.0)$ at $298 \mathrm{~K}$, using pNPP $\left(c=2 \mathrm{mmol} \mathrm{dm}^{-3}\right)$ as a substrate. The rate of inactivation was determined by fitting the experimental data to a single-exponential decay function.

\section{RESULTS}

Comparison of Kinetic Properties of Wild Type AP and Mutant Enzymes Carrying Mutations at Subunit Interface

It has been already shown that the T81A mutation, located at the subunit interface, influences the kinetic properties of AP. In Tris $/ \mathrm{HCl}\left(c\right.$ (Tris) $\left.=1 \mathrm{~mol} \mathrm{dm}^{-3}, \mathrm{pH}=8.0\right)$, the $k_{\text {cat }}$ of the T81A mutant was reduced almost twofold (36.98 $\left.\mathrm{s}^{-1}\right)$ compared to the wild type protein $\left(61.84 \mathrm{~s}^{-1}\right)$, while the $K_{m}$ $\left(7.3 \mu \mathrm{mol} \mathrm{dm}{ }^{-3}\right)$ did not change significantly $(7.8 \mu \mathrm{mol}$ $\left.\mathrm{dm}^{-3}\right){ }^{9}$ The kinetic properties of the double mutant, T81A/Q83L, were determined and compared to the wild type and T81A protein. The results are presented in Table 1. Affinity for the substrate, pNPP, and the competitive inhibitor, $\mathrm{P}_{i}$, described by respective kinetic constants $K_{m}$ and $K_{i}$, were the same for the wild-type and mutant enzymes, while the $k_{\text {cat }}$ values for the T81A and T81A/Q83L mutants were similar and reduced almost twofold compared to the wild-type enzyme.

\section{Phosphorescence Decay Measurement}

At room temperature, phosphorescence lifetime is directly correlated to the dynamic structure of the polypeptide chain in the surrounding environment of the chromophore group. ${ }^{12,13}$ The $\beta$-pleated sheet enveloping chromophore Trp109 stretches to the subunit interface establishing hydrogen bond mediated contacts with an equivalent $\beta$-pleated sheet of the neighboring subunit. ${ }^{8}$ Mutations introduced into the contact region that prevent hydrogen bond formation, could affect communication between active sites and the rigidity of the Trp109 environment. The rate of phosphorescence intensity decay of wild-type and mutant forms of AP in Tris/ $\mathrm{HCl}$ buffer at $293 \mathrm{~K}$ was found to follow an exponential dependence for all samples. Phosphorescence lifetime, $\tau$, determined for the wild-type protein was $1.49 \mathrm{~s}$, while the $\tau$ value for the T81A and T81A/Q83L mutant proteins was 1.50 and $2.13 \mathrm{~s}$, respectively. The determined phosphorescence lifetime indicates that Trp109 environment in the double mutant was more rigid compared to the wild type enzyme and the single mutant.

\section{Phosphorescence Quenching with Acrylamide}

Flexibility of a macromolecule can also be assessed by measuring the rate of diffusion of a molecule that quenches tryptophan phosphorescence. Ease of diffusion of a quencher in the vicinity of the phosphorescent tryptophan is described by a bimolecular rate constant $k_{\mathrm{q}}$ obtained from the gradient of the lifetime Stern-Volmer plot $\left(1 / \tau-1 / \tau_{0}=k_{\mathrm{q}}\right.$ [acrylamide]). The dependence of lifetime data versus acrylamide concentration yields a linear Stern-Volmer plot for wild type and mutant AP. The slope of the respective plots provides a bimolecular rate-quenching constant $k_{\mathrm{q}}=0.19 \mathrm{dm}^{3} \mathrm{~mol}^{-1} \mathrm{~s}^{-1}$ for wild-type AP, $0.13 \mathrm{dm}^{3} \mathrm{~mol}^{-1} \mathrm{~s}^{-1}$ for the T81A mutant and $0.32 \mathrm{dm}^{3} \mathrm{~mol}^{-1} \mathrm{~s}^{-1}$ for the T81A/Q83L double mutant, indicating that acrylamide diffuses somewhat less freely through the T81A protein than the wild-type enzyme, while the T81A/Q83L double mutant allows for structural variation of protein regions connecting surface and neighborhood of Trp 109 permitting faster acrylamide migration into the protein interior (Figure 1).

\section{Structural Stability}

Mutations introduced into the inner core of a protein molecule could reduce the stability of the protein fold, rendering it susceptible to inactivation by various agents. Structural stability of mutants was assessed by 


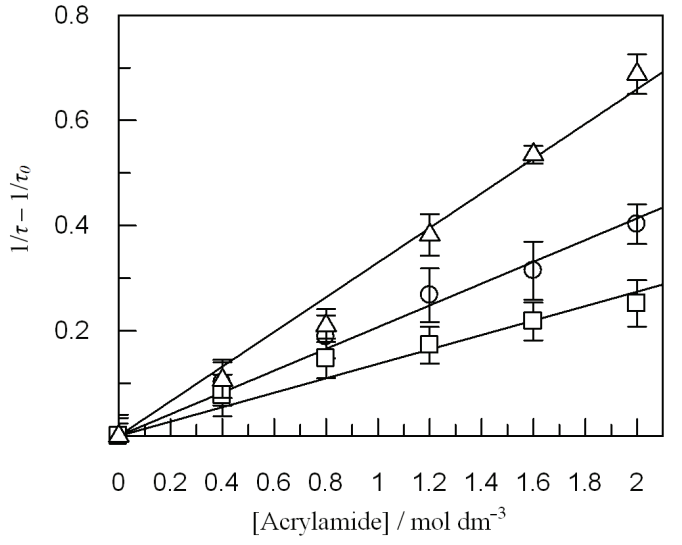

Figure 1. Lifetime Stern-Volmer plot for the quenching of AP by acrylamide in Tris/ $\mathrm{HCl}, c$ (Tris) $=20 \mathrm{mmol} \mathrm{dm}^{-3}, \mathrm{pH}=7.6, T$ = $293 \mathrm{~K}$; wild-type enzyme (circles), T81 A mutant (squares), T81A/Q83L mutant (triangles).

thermal denaturation. Alkaline phosphatase from E. coli is remarkably resistant to thermal denaturation. Inactivation of wild-type and mutant forms of AP was followed at $353 \mathrm{~K}$. Inactivation rate constants were obtained by fitting parameters of a single exponential curve function to residual activity data (Figure 2). Inactivation rate constants of $3.20 \times 10^{-3}$ and $1.64 \times 10^{-3} \mathrm{~s}^{-1}$ for the $\mathrm{T} 81 \mathrm{~A} / \mathrm{Q} 83 \mathrm{~L}$ and $\mathrm{T} 81 \mathrm{~A}$ mutant, ${ }^{9}$ respectively, were higher than the rate of inactivation determined for wild-type $\operatorname{AP}^{9}\left(7.98 \times 10^{-4} \mathrm{~s}^{-1}\right)$ (Table 1). Apparently mutations affecting hydrogen bond forming residues in the interface region reduced the thermal stability of mutant proteins, as shown by higher values of inactivation rate constants (Figure 2).

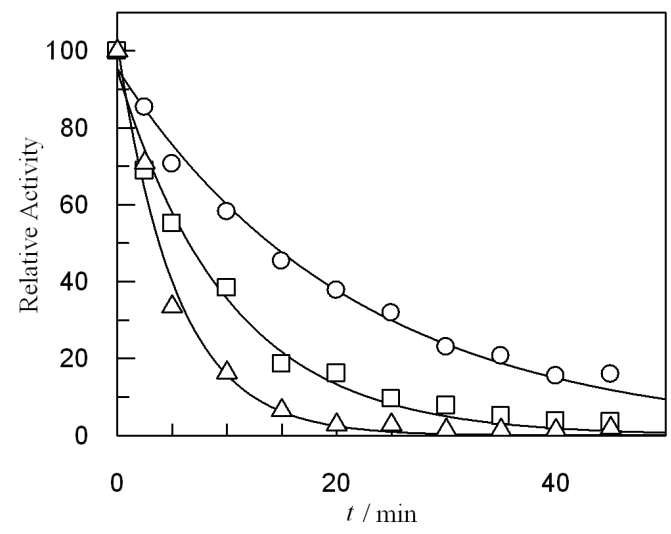

Figure 2. Relative activity $v s$. time plot for the inactivation of the wild-type enzyme ${ }^{9}$ (circles), T81A mutant ${ }^{9}$ (squares), T81A/Q83L mutant (triangles) AP from E.coli. The enzyme solution was incubated in Tris $/ \mathrm{HCl}, c$ (Tris) $=20 \mathrm{mmol} \mathrm{dm}$, $\mathrm{pH}=7.6, T=353 \mathrm{~K}$, followed by activity measurements in Tris $c$ (Tris) $=1 \mathrm{~mol} \mathrm{dm}^{-3}, \mathrm{pH}=8, T=298 \mathrm{~K}$. The rate of inactivation was determined by fitting the experimental data to a single exponential decay function.

\section{DISCUSSION}

Protein molecules show complex internal motions ranging from fast fluctuations of individual atoms, over loop and domain motions and conformational rearrangements, to slow breathing motions. Various structural motions could affect protein function in multiple ways. A conformational change induced by ligand binding may influence structural and binding properties of remote sites for the same or a structurally unrelated ligand. $^{26-30}$ The binding event could reduce or enhance protein motions affecting only the entropy of the system, enabling allosteric effects to be based solely on protein rigidity. ${ }^{10}$ Also, the dynamic properties of the active site could have significant influence on the rate of the catalytic step. Therefore coupling of chemical reactions to conformational change and dynamic properties of a protein molecule is an intriguing area of interest.

Alkaline phosphatase from $E$. coli is a dimeric enzyme rich in allosteric interactions and represents a good model for studying the relationship between conformation, dynamics and catalytic properties. Positive cooperative interactions have been described for the AP M1 metal binding sites, while negative cooperative interactions have been detected for the M3 metal binding sites. ${ }^{31,32}$ Apparently negative cooperative kinetic behavior has been supported by a model describing an enzyme with inherently unequal subunits. ${ }^{7}$ It has been proposed that enzyme asymmetry with subunits differing in affinity for the substrate and product, could be used to favor enhanced product release. An important feature of the proposed model is a conformational change converting a high affinity subunit to a low affinity subunit, and vice versa. The rate of conformational change along with the reaction rate could be increased by a ligand, in the case of $\mathrm{AP} \mathrm{a} \mathrm{Mg}^{2+}$ ion, inducing the same conformational change as the substrate or the product. If such a ligand is present at a concentration higher than that of the substrate, it would accordingly increase the reaction rate. Such a model relies upon subunit communication, and focuses the attention on the possible role of the subunit interface in the kinetic mechanism. It has been demonstrated that mutations introduced at subunit interface could have a profound effect on the kinetic properties. ${ }^{33}$

A mutation, introduced into the subunit interface region, presumably involved in coupling between the active sites, was used to assess the importance of such communication for enhanced catalysis. Neighboring $\beta$-sheets are connected with hydrogen bonds between Thr81 and Gln83 from adjacent subunits (Figure 3). ${ }^{8}$ Kinetic properties of a T81A mutant have been determined in Tris/ $\mathrm{HCl}$ buffer $\left(c\right.$ (Tris) $=1 \mathrm{~mol} \mathrm{dm}^{-3}, \mathrm{pH}=$ 8.0). Breaking a single hydrogen bond in that region resulted in $k_{\text {cat }}$ reduction from $61.84 \mathrm{~s}^{-1}$ to $36.98 \mathrm{~s}^{-1}$, 


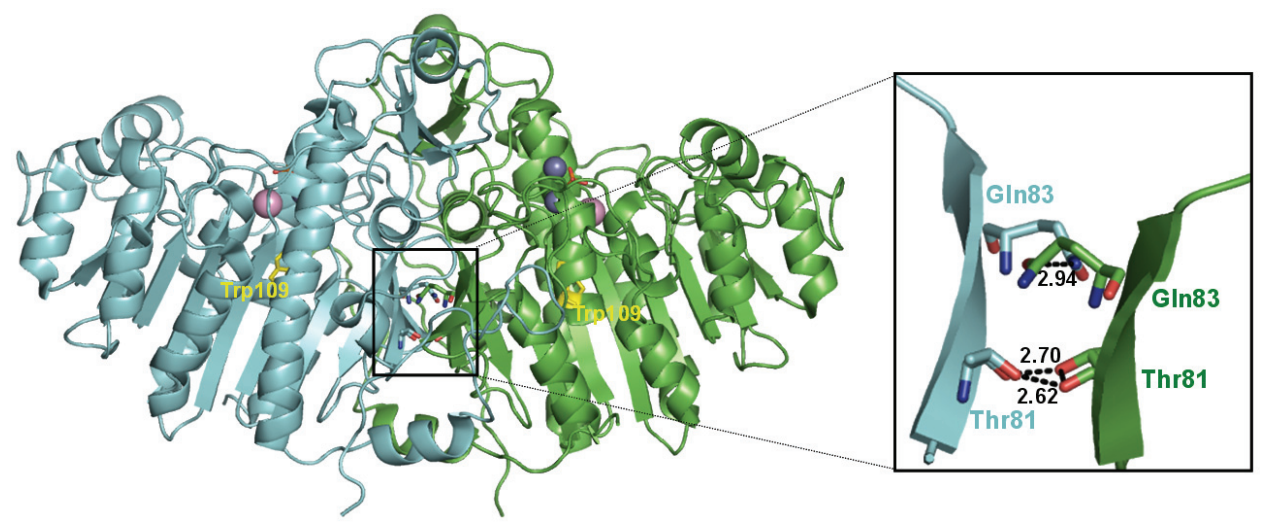

Figure 3. Crystal structure of dimeric alkaline phosphatase from E.coli, showing Thr81 and Gln 83 at subunit interface and hydrogen bonds between them (enlarged portion of subunit interface). Tryptophan 109, metal ions and phosphate bound in the active site region are displayed: tryptophan (yellow), zinc ions (blue), magnesium ion (pink), phosphate (red).

while the affinity for the substrate (pNPP), and the competitive inhibitor $\left(\mathrm{P}_{i}\right)$ remained the same. ${ }^{9}$ Kinetic properties of a double mutant were virtually the same as for the single mutant protein, indicating that the kinetically important bond between the subunits, or the communication between active sites, was completely impaired by removing a single hydrogen bond in the subunit interface region. At a same time, removal of the second hydrogen bond resulted in further decrease in structural stability, as evidenced by faster thermal inactivation. The double mutant, T81A/Q83L, was inactivated at a single order constant of $3.20 \times 10^{-3} \mathrm{~s}^{-1}$ and compared to $1.64 \times 10^{-3} \mathrm{~s}^{-1}$ for the single mutant $\mathrm{T} 81 \mathrm{~A}^{9}$ and $7.98 \times 10^{-4} \mathrm{~s}^{-1}$ for wild type AP. ${ }^{9}$

The nature of the change in protein structure, which led to altered kinetic properties, was examined by measuring the phosphorescence properties of Trp109. The correlation between rigidity of protein structure and kinetic properties could indicate whether a conformational change or alteration in the rigidity of a protein molecule should be sought as the source of allosteric effects in AP from E. coli.

Trp109 environment in the T81A mutant has same rigidity as the wild type enzyme, as determined by the phosphorescence lifetime $\tau$ of $1.49 \mathrm{~s}$ and $1.50 \mathrm{~s}$ for the wild type and the T81A mutant, respectively. The double mutant T81A/Q83L has more rigid structure in accordance to the phosphorescence lifetime of $2.13 \mathrm{~s}$. Possible explanation of increased rigidity could be denser packing of protein core upon replacement of more polar threonine and glutamine side chains with hydrophobic alanine and leucine side chains. Significantly lower $k_{\text {cat }}$ of the T81A mutant compared to the wild type enzyme is not accompanied by significant change of phosphorescence lifetime. Also, significant increase of the phosphorescence lifetime of the double T81A/Q83L mutant compared to a single T81A mutant is not followed by any change in $k_{\text {cat }}$, indicating that the reduction of $k_{\text {cat }}$ is not due to alteration of the dynamic properties of the protein. Most likely, breaking of a specific link involved in transmission of conformational change is responsible for the reduced catalytic power of the mutant enzymes. Such conclusion is corroborated by the measurement of a quenching constant that describes the rate of acrylamide migration into the neighborhood of the phosphorescent Trp109. The ease of migration is dependent on open pathway or structural fluctuations permitting the access of acrylamide into the protein interior. According to the measured quenching constants, $0.19 \mathrm{dm}^{3} \mathrm{~mol}^{-1} \mathrm{~s}^{-1}$ for wild type AP, $0.13 \mathrm{dm}^{3} \mathrm{~mol}^{-1} \mathrm{~s}^{-1}$ for the T81A mutant and $0.32 \mathrm{dm}^{3} \mathrm{~mol}^{-1} \mathrm{~s}^{-1}$ for the $\mathrm{T} 81 \mathrm{~A} / \mathrm{Q} 83 \mathrm{~L}$ mutant, the largest difference in the rate of acrylamide migration is observed between the two mutant enzymes, displaying the same kinetic properties.

\section{CONCLUSION}

Mutations introduced at the subunit interface of AP reduced the $k_{\text {cat }}$ of the single T81A (Reference 9) and the double T81A/Q83L mutant protein. Structural stability was also affected, the T81A/Q83L mutant being the least stable, the T81A mutant displaying an intermediate stability, ${ }^{9}$ while wild type AP was the most stable, ${ }^{9}$ as evidenced by the rate of thermal denaturation. Alteration of phosphorescence lifetime and rate of phosphorescence quenching by acrylamide did not parallel changes in kinetic properties of the mutant proteins. Mutant proteins, displaying the same $k_{\text {cat }}$, had different dynamic properties, indicating that in case of AP the catalytically important communication between the subunits is most likely mediated by a conformational change rather than altered rigidity of the protein structure.

Acknowledgements. This work was supported by Croatian Ministry of Science, Education and Sport, grant no. 1770000000-2962. 


\section{REFERENCES}

1. S. A. Bernhard, M. F. Dunn, P. L. Luisi, and P. Schack, Biochemistry 9 (1970) 185-192.

2. M. Lazdunski, C. Petitclerc, D. Chappelet, and C. Lazdunski, Eur. J. Biochem. 20 (1971) 124-139.

3. A. Levitzki, W. B. Stallcup, and D. E. Koshland Jr, Biochemistry 10 (1971) 3371-3378.

4. W. B. Stallcup, and D. E. Koshland Jr, J. Mol. Biol. 80 (1973) $41-62$.

5. W. B. Stallcup, D. E. and Koshland Jr, J. Mol. Biol. 80 (1973) $77-91$.

6. S. Orhanović, M. Pavela-Vrančič, and M. Flogel-Mršić, Acta. Pharm. 44 (1994) 87-95.

7. S. Orhanović and M. Pavela-Vrančič, Eur. J. Biochem. 270 (2003) 4356-4364.

8. E. E. Kim and H. W. Wyckoff, Clin. Chim. Acta 186 (1990) $175-187$.

9. S. Orhanović, V. Bučević-Popović, M. Pavela-Vrančić, D. Vujaklija, and V. Gamulin, Int. J. Biol. Macromol. 40 (2006) $54-58$.

10. N. Popovych, S. Sun, R. H. Ebright, and C. G. Kalodimos, Nat Struct. Mol. Biol. 13 (2006) 831-838.

11. M. L. Savioti and W. C. Galley, Proc. Nat. Acad. Sci. USA 71 (1974) 4154-4158.

12. M. Gonnelli and G. B. Strambini, Biochemistry 34 (1995) 13847-13857.

13. G. B. Strambini and M. Gonnelli, J. Am. Chem. Soc. 117 (1995) 7646-7651.

14. P. Cioni and G. B. Strambini, J. Mol. Biol. 207 (1989) 237-247.

15. G. B. Strambini and M. Gonnelli, Biochemistry 29 (1990) 196-203.

16. G. B. Strambini, P. Cioni, A. Peracchi, and A. Mozzarelli,
Biochemistry 31 (1992) 7535-7542.

17. J. M. Vanderkooi, D. B. Calhoun, and S. W. Englander, Science 236 (1987) 568-569.

18. P. Cioni and G. B. Strambini, Biochim. Biophys. Acta 1595 (2002) 116-130.

19. J. M. Vanderkooi and J. W. Berger, Biochim. Biophys. Acta 976 (1989) 1-27.

20. J. A. Schauerte, D. G. Steel, and A. Gafni, Methods Enzymol. 278 (1997) 49-71.

21. S. Papp and J. M. Vanderkooi, Photochem. Photobiol. 49 (1989) 775-784.

22. P. Cioni and G. B. Strambini, J. Am. Chem. Soc. 120 (1998) 11749-11757.

23. P. Cioni, L. Piras, and G. B. Strambini, Eur. J. Biochem. 185 (1989) 573-579

24. M. M. Bradford, Anal. Biochem. 72 (1976) 248-354.

25. D. D. Banks and B. A. Kerwin, Anal. Biochem. 324 (2004) 106 114.

26. J. M. Yon, D. Perahia, and C. Ghelis, Biochimie 80 (1998) 33-42.

27. D. Kern and E. R. P. Zuiderweg, Curr. Opin. Struct. Biol. 13 (2003) $748-757$.

28. H. J. C. Berendsen and S. Hayward, Curr. Opin. Struct. Biol. 10 (2000) 165-169.

29. A. Peracchi and A Mozzarelli, Biochim. Biophys. Acta 1814 (2011) 922-933.

30. J. D. McGeagh, K. E. Ranaghan, and A. J. Mulholland, Biochim Biophys. Acta 1814 (2011) 1077-1092.

31. J. F. Chlebowski, S. Mabrey, and M. C. Falk, J. Biol. Chem. 254 (1979) 5745-5753.

32. G. Cathala and C. Brunel, J. Biol. Chem. 250 (1975) 6046-6053.

33. C. C. Hwang, C. N. Hsu, T. J. Huang, S. J. Chiou, and Y. R. Hong, Arch Biochem. Biophys. 490 (2009) 36-41. 